I nf I uence of aggregate material s char acteri stics on the drying shri nkage properti es of nortar and concrete

\begin{tabular}{|l|l|}
\hline 著者 & ZHANG Wenyan, ZAKARI A Mohamed, HAMA Yuki o \\
\hline $\begin{array}{l}\text { j our nal or } \\
\text { publ i cat i on t i t l e }\end{array}$ & Const ruct i on and bui I di ng mat er i al s \\
\hline vol une & 49 \\
\hline page range & $500-510$ \\
\hline year & $2013-12$ \\
\hline URL & ht t p: //hdl . handl e. net /10258/2655 \\
\hline
\end{tabular}


I nf I uence of aggregate material s char acteri stics on the drying shri nkage properti es of nortar and concrete

\begin{tabular}{|l|l|}
\hline 著者 & ZHANG Wenyan, ZAKARI A Mohamed, HAMA Yuki o \\
\hline $\begin{array}{l}\text { j our nal or } \\
\text { publ i cat i on t i t l e }\end{array}$ & Const ruct i on and bui I di ng mat er i al s \\
\hline vol une & 49 \\
\hline page range & $500-510$ \\
\hline year & $2013-12$ \\
\hline URL & ht t p: //hdl . handl e. net /10258/2655 \\
\hline
\end{tabular}




\section{Highlights}

- Fine aggregates significantly affect the drying shrinkage in mortar, but concrete.

- Limestone sand and blast furnace slag sand can reduce the mortar drying shrinkage.

- Coarse aggregate characteristics play an important role on the concrete drying shrinkage property.

- Coarse aggregate strain, specific surface area and pore structure of coarse aggregates are investigated.

- Total amount of water content parameter on drying shrinkage is introduced. 


\title{
Influence of Aggregate Materials Characteristics on the Drying Shrinkage Properties of Mortar and Concrete
}

\author{
Wenyan Zhang ${ }^{\text {a }}$, Mohamed Zakaria ${ }^{\text {a, b }}$, Yukio Hama ${ }^{\text {a, * }}$ \\ ${ }^{a}$ College of Environmental Technology, Graduate School of Engineering, Muroran Institute of \\ Technology, 27-1 Mizumoto, Muroran 050-8585, Japan \\ ${ }^{\mathrm{b}}$ Department of Civil Engineering, Faculty of Engineering, Aswan University, \\ Aswan 81542, Egypt
}

Corresponding author:

E-mail address: hama@mmm.muroran-it.ac.jp～Tel: +81-143-46-5211

\begin{abstract}
:
This paper presents an experimental study to clarify the effect of various aggregate materials characteristics on the drying shrinkage property in mortar and concrete specimens incorporating fourteen kinds of fine aggregate materials (standard sand, natural sand, marine sand, various kinds of slag-type sand, and various kinds of crushed sand) and three kinds of coarse aggregate materials (andesite gravel, hard sandstone gravel, and limestone gravel). The test results revealed that the characteristics of fine and coarse aggregate materials play an important role in controlling the drying shrinkage property of mortar and concrete, respectively. Limestone sand and blast furnace slag sand can restrain the drying shrinkage of mortar specimens about $22 \%$ and $30 \%$, respectively, compared to the case of mortar incorporating standard sand. The drying shrinkage strain of concrete specimens proportionally increases with the increase of aggregate shrinkage strain, specific surface area and 6 to $30 \mathrm{~nm}$ in diameter pore volume of aggregates, which implies the significant influence of aggregate characteristics on drying shrinkage development in concrete. It was also found that the drying shrinkage property in concrete can be affected by the static modulus of elasticity and total amount of water content, in which the water absorption ratio, unit mass of aggregate and unit water content were considered. Finally, the experimental results presented are useful information for providing a good perspective for the concrete mixture design practices taking into consideration that concrete drying shrinkage could be controlled by appropriate aggregate characteristics and reducing the total amount of water content.
\end{abstract}

Keywords: Drying shrinkage strain, Static modulus of elasticity, Aggregate shrinkage strain, Specific surface area, Pore size distribution, Total amount of water content 


\section{Introduction}

Drying shrinkage, which may lead to inevitable cracking in many concrete structures [1], can be defined as the volumetric change owing to the drying of concrete. This change in volume of the concrete is related to the volume of water lost. The loss of free water, which occurs first, may induce shrinkage. As the drying process of the concrete continues, the adsorbed water held by hydrostatic tension in the small capillaries is reduced significantly [2]. The loss of the water (free water and adsorbed water) may lead to tensile stresses, which force concrete to shrink causing cracks that can adversely affect the structural performances, such as durability and serviceability, if not appropriately considered in the design stage [3-5].

In order to ensure the high performance of concrete structures, the upper limit of long-term drying shrinkage strain for concrete should not exceed 800 micron, as defined in the revision of Japanese Architectural Standard Specification, JASS 5 of 2009, which has been discussed by many researchers $[6,7]$. It is worthy to mention that various kinds of aggregate materials have been used in the concrete production since last decades, among them aggregate comes from natural resources or from industry in the form of by-products. The continuous need of concrete structures for housing is increasing rapidly and could be estimated to be more than two million units. That would consume huge amounts of construction materials such as natural sand, marine sand, coarse aggregate and crushed stones, which in turn may affect the global environment $[8,9]$. Furthermore, the use of industrial by-products has been given attention in the concrete technology research since the beginning of the twentieth century [10-12]. Therefore, with the depletion of natural aggregate resources, the research on by-products aggregate materials, such as copper slag sand and blast furnace slag sand, becomes an important issue. However, it is difficult to evaluate if the determined upper limit by JASS 5 for drying shrinkage and its properties can be valid for concrete incorporating such kinds of by-products aggregates. Hence, more experiments are quite needed to clarify the raising point.

It is well known that drying shrinkage is an everlasting process when concrete is subjected to drying conditions; this can be explained by the loss of water held in capillary pores of cement paste [13]. The finer the capillary pores the more is the shrinkage. However, it was concluded in previous researches $[7,13,14]$ that there is important influence of other parameters on the drying shrinkage properties of concrete, that are mineral admixtures, cement type, chemical admixtures and aggregate quantity. Also, it was revealed that the drying shrinkage of concrete progresses with the increase of its unit water content or water/cement ratio, which has been referred to as the major factor affecting the drying shrinkage properties [7, 13]. Hansen et al. [15-18] reported that the coarse aggregate has an influence on the long-term drying shrinkage of concrete. Concrete 
shrinks less than mortar, and mortar shrinks less than cement paste. The aggregates play an important role in restraining the shrinkage of the cement matrix, which could reduce the shrinkage of concrete compared to plain hardened cement paste [19], but the shrinkage property of aggregate itself has not been fully investigated.

In the previous studies [18-21], it was observed that the magnitude of concrete drying shrinkage could be reduced by using limestone aggregates, and the static elastic modulus of aggregate has a considerable effect on the shrinkage behavior. Moreover, it was found that not only the modulus of elasticity, but also the shrinkage strain of normal aggregate and lightweight aggregate can control the drying shrinkage of concrete [22, 23], which should be paid more attention. Snowdon and Edwards [24] revealed that aggregate materials having the property of low water absorption ratio can reduce the aggregate shrinkage for the case of normal coarse aggregates. Nevertheless, it could not be used to comprehensively evaluate the shrinkage of different kinds of coarse aggregates. This is based on the findings by Goto et al. [25] who revealed that the lightweight aggregate with higher water absorption ratio has a relatively smaller shrinkage strain than the normal aggregate with lower water absorption ratio, implying that there is another parameter affecting the drying shrinkage that is the aggregate pore structure. The lightweight aggregates usually exhibit relatively greater volume of large size pores and smaller volume of micro pores compared to the normal aggregates, resulting in decreasing the internal surface area, which is related to the pore structure characteristics of aggregate materials. Also, it has been reported that the volumetric change of aggregate caused by shrinkage can be controlled by the aggregate specific surface area $[25,26]$. In spite of the preceding studies, the behavior of the shrinkage property of aggregate materials inside the concrete matrix is still complicated and has not been fully clarified. Most of those studies concerned with natural sand as fine aggregate materials, while the studies about the drying shrinkage evolution in concrete incorporating slag-type fine aggregates are particularly few [27].

Based on the above discussion, it is obvious that extensive research on the drying shrinkage of mortar and concrete incorporating various kinds of fine and coarse aggregate materials is quite needed to understand the shrinkage properties, maintain the structural performances of concrete, investigate the applicability of slag-type aggregates, and save the natural resources as well. Therefore, the objective of the current study is to clarify the influence of fine aggregate materials (Japanese Industrial Standard - JIS standard sand, natural sand, marine sand, various kinds of slag-type sand, and various kinds of crushed sand) and coarse aggregate materials (andesite gravel, hard sandstone gravel and limestone gravel) on the drying shrinkage evolution in mortar and concrete by discussing how their characteristics can affect the developed drying shrinkage 
strain. Various characteristics of aggregate materials related to shrinkage property, which are aggregate shrinkage strain, aggregate pore structure and aggregate specific surface area, were examined. Moreover, the effects of static modulus of elasticity and total amount of water content on the drying shrinkage were discussed. The measurements of aggregate pore structure and aggregate specific surface area were conducted by mercury intrusion porosimetry (MIP) and water vapor adsorption measurement, respectively. Also, the static modulus of elasticity was measured as a stress to strain ratio value for hardened cement based materials according to JIS A 1149 compression test, and total amount of water content was calculated by the water absorption ratio, unit mass of aggregate and unit water content. Finally, the obtained results are valuable information to enhance the practical design codes for drying shrinkage of mortar and concrete, and open the door to further studies, in particular, regarding the applicability of by-products fine aggregate materials in the concrete production field.

\section{Experimental work}

The experiments were designed to achieve the objective of this study, which is to evaluate how the characteristics of aggregate materials can affect the development of drying shrinkage in mortar and concrete specimens made with various kinds of fine and coarse aggregate materials brought from different producing areas. The description of used aggregate materials (14 kinds of fine aggregates and 3 kinds of coarse aggregate materials), preparation of test specimens (mortar and concrete specimens), and applied test procedures (JIS A 1129-3 dial gauge method, JIS A 1149 compression test, attaching strain gauge to aggregate surface method, MIP method and water vapor adsorption method) for the experimental measurements (the drying shrinkage evolution, static modulus of elasticity, coarse aggregate shrinkage strain, coarse aggregates pore structure and aggregates specific surface area, respectively) are discussed in this section as following.

\subsection{Materials}

The physical and chemical properties (chemical composition, density and blaine fineness) of ordinary Portland cement (OPC), which was used in casting of all tested mortar and concrete specimens, are given in Table 1. Fourteen kinds of fine aggregate materials (JIS standard sand, natural sand, marine sand, various kinds of slag-type sand, and various kinds of crushed sand) were used in the preparation of mortar specimens, while, three kinds of coarse aggregate materials (andesite gravel, hard sandstone gravel and limestone gravel) were used for concrete specimens. The physical properties of used fine and coarse aggregate materials are described in 
Table 2. Concerning the given symbols for the various kinds of fine aggregates in Table 2, symbols with lowercase letters refer to fine aggregate materials used in casting concrete specimens (which are cu, b, 1 and k fine aggregates), except natural sand (s) which was used in the preparation of both mortar and concrete specimens containing this type of fine aggregate materials. While other symbols with uppercase letters refer to fine aggregate materials used in preparing only mortar specimens (which are $\mathrm{N}, \mathrm{U}, \mathrm{Cu}, \mathrm{Cu} 2.5, \mathrm{Cu} 1.2, \mathrm{Cul}, \mathrm{BFS}$, LTA, LTB, LK, LG, $\mathrm{K}$ fine aggregates), among them, fine aggregates with different symbols under the same kind of fine aggregate materials, such as slag-type sand and limestone sand, belong to different producing areas.

The particle size distribution, which was determined by the sieve analysis method, of fine aggregates used in preparing mortar specimens can be seen in Fig. 1. It can be revealed from Fig. 1 and Table 2 that the maximum size of all investigated fine aggregates was $5 \mathrm{~mm}$, except for JIS standard sand, $\mathrm{Cu} 2.5$ and Cu1.2 slag-type sand with the maximum size of $2.5 \mathrm{~mm}$. The sieve analysis results for particle size distribution of fine and coarse aggregates, which have been used in casting concrete specimens, have been plotted in Fig. 2 (a) and Fig. 2 (b), respectively. From Fig. 2 (a) and Table 2, it is clear that the maximum fine aggregate size of cu and b sand was 2.5 $\mathrm{mm}$, while that of $\mathrm{s}, 1$ and $\mathrm{k}$ was $5.0 \mathrm{~mm}$. The coarse aggregate sieve analysis result reveals that the three kinds of used coarse aggregate have the same maximum aggregate size of $25 \mathrm{~mm}$, as shown in Fig. 2 (b) and Table 2.

\subsection{Specimens}

\subsubsection{Mortar}

All mortar specimens were casted using OPC, fine aggregates and water, with 0.50 water-to-cement ratio $(W / C)$ and 1:3 cement-to-sand ratio. 14 kinds of mortar specimens were prepared, all of which with the same conditions, except the kind of fine aggregate materials used. Table 3 shows the typical mix proportion for $\mathrm{N}$ mortar specimen incorporating Japanese Industrial Standard (JIS) standard sand. In order to compare the influence of various kinds of fine aggregate materials on drying shrinkage in mortars, the mix proportions for all mortar specimens were decided based on JIS standard mortar, see Table 3, by using constant volume of fine aggregate materials. Mortar specimens were casted into 40 x 40 x $160 \mathrm{~mm}$ prisms.

\subsubsection{Concrete}

In the preparation of concrete specimens, five kinds of fine aggregate materials, which are natural sand (s), copper slag sand (cu), blast furnace slag sand (b), limestone sand (l) and hard 
sandstone sand (k), and three kinds of coarse aggregate materials, which are andesite gravel (A), limestone gravel (L) and hard sandstone gravel (H), were used, as shown in Table 4. Concrete specimens were arranged into two groups, which are group A and group B, as described in Table 5, with different mix proportion for aggregate ratio. Group $\mathrm{A}$ is designed to investigate the effect of fine and coarse aggregate materials on the drying shrinkage property. Concrete specimens, in group A, were designed with $46 \%$ by volume aggregate ratio, $185 \mathrm{~kg} / \mathrm{m}^{3}$ unit water content and 0.50 water-to-cement ratio. The mix proportion of concrete specimens in group B was changed in order to explore the effect of unit water content on the concrete drying shrinkage. In order to achieve the target slump of $180 \pm 15 \mathrm{~mm}$ in group $\mathrm{B}$, the unit water content was adjusted to 225 $\mathrm{kg} / \mathrm{m}^{3}$ instead of $185 \mathrm{~kg} / \mathrm{m}^{3}$ for A group concrete, without the addition of any chemical agent, and the fine aggregate ratio was set to $40.3 \%$ by volume, but with the same water-cement ratio (W/C $=0.50$ ) as in group A, as shown in Table 5 for mix proportions and fresh properties of concrete specimens in groups A and B. The air content and slump were measured as index of the fresh properties in accordance with JIS A 1128 pressure method and JIS A 1101 slump test method, respectively. Concrete specimens were casted into 100 x 100 x 400 mm prisms.

\subsection{Test methods}

\subsubsection{Length change and mass loss}

The measurements of length change as scale of the drying shrinkage of mortar and concrete prisms were conducted based on JIS A 1129-3 dial gauge method. Mortar and concrete specimens were demoulded after 1 day, and cured at $20^{\circ} \mathrm{C}$ in water for 6 days. After curing, the specimens were placed in a control chamber at $20^{\circ} \mathrm{C}$ and $60 \%$ relative humidity for the measurement. The initial gauge length of mortar and concrete prisms was measured by the dial gauge and consecutive readings of the change in gauge length were obtained for 91 days. Each observed data point plotted in the figures, which discuss the drying shrinkage evolution (for example Fig. 3 and Fig. 4) in mortar and concrete specimens, is the mean value of drying shrinkage measurements for three experimental prisms with the typical conditions. Also, the mass loss measurements of mortar and concrete prisms were taken corresponding to the length change measurements of typical prisms. Further measurements of drying shrinkage strains were taken for concrete specimens at the drying time of 1029 days to evaluate the influence of various kinds of aggregates on the behavior of drying shrinkage at different drying time. Based on the comparison of drying shrinkage strains at different drying times given in section 3.1.2 (see Fig. 5), it can be revealed that drying shrinkage strains measured at drying time of 91 days showed the same tendency, with high correlation coefficient, as the ones measured at drying time of 1029 days for 
various kinds of aggregates. This is the reason that measured drying shrinkage strains at 91 days were used to evaluate how various aggregate kinds can affect the drying shrinkage.

\subsubsection{Static modulus of elasticity}

The measurements of 28 days static modulus of elasticity $(E)$ for mortar and concrete specimens with various kinds of aggregate materials were conducted in compression based on the JIS A 1149. Dimensions of mortar and concrete cylinders were $\$ 50 \times 100 \mathrm{~mm}$ and $\$ 100 \times 200$ $\mathrm{mm}$, respectively.

\subsubsection{Coarse aggregates shrinkage strain}

Shrinkage strain of coarse aggregate, as one of the major parameters affecting the drying shrinkage property of concrete, could be measured by strain gauge method. The different shapes and angularities of aggregates may influence the aggregate characteristics, and it has been verified in the previous study [28] that variation among particles in shrinkage strain of coarse aggregate is intrinsic and could also be measured by the simplified unidirectional strain measurement under the assumption of ignoring multi-axial strain field. Thus, in the experiment, the coarse aggregate surface was polished and attached by strain gauge, then was sealed with waterproof butyl rubber tape. The coarse aggregates, which were greater than $15 \mathrm{~mm}$ size, were immersed in water for 2 weeks to reach the saturated condition, which was referred to as the initial length. Then, the aggregates were placed, in the same condition with the investigated concrete specimens, and the coarse aggregates shrinkage strains were measured by the strain gauge method until the shrinkage strain curve became smooth and steady for two weeks. Each obtained data point drawn in the figures for aggregate shrinkage strain (for example Fig. 5) is the mean value of shrinkage strain measurements for three coarse aggregate samples with the same conditions.

\subsubsection{Coarse aggregates pore structure}

The pore structure of coarse aggregate materials could be captured by the mercury intrusion porosimetry (MIP) method, in a typical way to the measurement of pore size distribution in cement based materials [29-31]. The pore structure of various kinds of coarse aggregate materials, which were ground and graded first with a diameter of $5 \mathrm{~mm}$, was examined by subjecting them firstly to the drying conditions for two days. Then, pore size distribution was determined with MIP method using Autopore Master33 porosimeter, in which a hydraulic pump generating the pressure and a contact sensor were used to measure the mercury volume. The surface tension of 
the mercury and the mercury density were $0.480 \mathrm{~N} / \mathrm{m}$ and $13.546 \mathrm{~g} / \mathrm{ml}$, respectively, with assuming a contact angle of $140^{\circ}$.

\subsubsection{Aggregates specific surface area}

The specific surface area of the investigated coarse aggregates, which are andesite gravel (A), limestone gravel (L) and hard sandstone gravel (H), as well as the natural sand fine aggregate, was measured by water vapor adsorption method using a hydrosorb1000. Before measuring the specific surface area of aggregate materials, it is necessary to remove the moisture inside aggregate materials by drying process at the baking temperature of $100^{\circ} \mathrm{C}$ for two days. The specific surface area of aggregate materials could be obtained based on the Brunauer-Emmett-Teller (BET) analysis theory $[32,33]$, which has been successfully applied in research and industry patents [34], and hence can be used effectively in evaluating the influence of aggregate kind on the drying shrinkage property of concrete.

\section{Results and discussion}

3.1 Drying shrinkage behavior in mortar and concrete

\subsubsection{Drying shrinkage behavior in mortar specimens}

The 91 days drying shrinkage strains of mortar specimens made with natural sand (N, s, and $U$ ), slag-type sand $(\mathrm{Cu}, \mathrm{Cu} 2.5, \mathrm{Cu} 1.2, \mathrm{BFS}$, and $\mathrm{Cul})$, crushed limestone sand (LTA, LTB, LK, and LG) and other crushed sand (K and F) are plotted in Fig. 3. It is obvious from the figure that the drying shrinkage strains of mortar specimens incorporating natural sand (s), hard sandstone sand (K) and granite sand (F) are relatively greater than the drying shrinkage strain for mortar specimen with JIS standard sand (N). Conversely, mortar specimens made with slag-type sand showed a much decreasing tendency of 91 days drying shrinkage strain compared with the case of JIS standard sand mortar, especially the mortar specimen incorporating blast furnace slag sand (BFS), which exhibited the smallest drying shrinkage value $\left(787 \times 10^{-6}\right)$ among all investigated mortars, as shown in Fig. 3. It is interesting to notice that mortar specimens made with limestone sand showed a little decreasing tendency for 91 days drying shrinkage strains compared with shrinkage strains of JIS standard sand mortar specimen. The increasing/decreasing tendency of drying shrinkage strains in investigated mortars specimens can be attributed to the characteristics of used fine aggregate materials, which are specific surface area, water absorption ratio, and dried density. The values of 91 days drying shrinkage strains in mortar specimens made with limestone sand (LG), and blast furnace slag sand (BFS) are $986.4 \times 10^{-6}$ and $787 \times 10^{-6}$, respectively, meaning that they are about $22 \%$ and $30 \%$, respectively, smaller than the drying shrinkage strain of mortar 
with JIS standard sand, which is $1107 \times 10^{-6}$. Also, it can be noticed from Fig. 3 that mortar specimens which brought from various producing areas, for example mortars with slag-type sand $(\mathrm{Cu}, \mathrm{Cu} 2.5, \mathrm{Cu} 1.2, \mathrm{BFS}, \mathrm{Cul})$, experienced different shrinkage strain, although they belong to the same type fine aggregate materials. From the obtained observation of drying shrinkage behavior in mortars with various kinds of fine aggregate materials, as shown in Fig. 3, it can be inferred that the kind of fine aggregate materials and their characteristics have a significant effect on the drying shrinkage strain of mortar, and that resulted in varying the drying shrinkage strains of investigated mortar specimens from $787 \times 10^{-6}$ to $1107 \times 10^{-6}$.

\subsubsection{Drying shrinkage behavior in concrete specimens}

The drying shrinkage strain development of the investigated concrete specimens in groups A and $\mathrm{B}$ is shown in Fig. 4 until 91 days drying time. Hence, the influence of fine aggregates, coarse aggregates, and unit water content on drying shrinkage can be clarified from the figure.

In Fig. 4 (a), the relationship between drying shrinkage and drying time for concrete specimens (Acuk-A, Abk-A, Ak-A, Al-A, As-A) with the same conditions, except the kind of fine aggregate materials, is given. Five kinds of fine aggregate materials, which are copper slag sand, blast furnace slag sand, limestone sand, hard sandstone sand and natural sand, were used in the comparison in addition to andesite coarse aggregate. As seen from Fig. 4 (a), the drying shrinkage strain-drying time relationships of the studied specimens, except Al-A concrete specimen with limestone sand, are nearly identical. It can be revealed that fine aggregate materials have insignificant influence on the drying shrinkage in concrete specimens, in contrary to its obvious influence on the drying shrinkage in mortar specimens. However, in concrete, the magnitude of drying shrinkage strain is mainly affected by the richness of concrete that is coarse aggregate, its volume, size and modulus of elasticity. The reason is that the coarse aggregate in concrete represents the major portion of the concrete volume, and hence can restrain the drying shrinkage. The amount of fine aggregate was limited to $46 \%$ of the total aggregates volume, so the volume of fine aggregate is smaller to coarse aggregate and could not cause such a strong influence on the drying shrinkage of concrete. It is clear from Table 5 that both limestone fine aggregate and limestone coarse aggregate have relatively small water absorption ratio, and this is why the specimens incorporating such kind of aggregates experienced a little smaller drying shrinkage strains.

Figure 4 (b) shows the drying shrinkage-drying time relationship for concrete specimens with the identical condition, but the kind of coarse aggregate materials. Three kinds of coarse aggregate materials, which are andesite aggregate (A) for As-A concrete specimen, limestone 
aggregate (L) for Ls-A concrete specimen, and hard sandstone aggregate $(\mathrm{H})$ for Hs-A concrete specimen, were examined. It can be revealed from the figure that the kind of coarse aggregates and its characteristics has a remarkable effect on the drying shrinkage evolution of concrete. The magnitude of concrete drying shrinkage are generally smaller than the drying shrinkage of mortars at the same age, due to the effect of coarse aggregate on drying shrinkage. Concrete specimens with andesite gravel (As-A) exhibited the greatest drying shrinkage strains, while concrete specimens with limestone (Ls-A) experienced the lowest drying shrinkage strains among the three investigated kinds of coarse aggregate materials, which is consistent with those in the previous studies $[20,21]$. The reason for this behavior can be explained by the influence of the coarse aggregate characteristics, such as coarse aggregate shrinkage strain, specific surface area of aggregate, absorption ratio, and pore structure of coarse aggregate, as will be discussed in the following sections.

The effect of water unit content on drying shrinkage evolution can be revealed from Fig. 4 (c), in which the relationship between drying shrinkage and drying time for concrete specimens in groups A and B is drawn. Specimens in group A were designed to have $185 \mathrm{~kg} / \mathrm{m}^{3}$ unit water content, while unit water content was $225 \mathrm{~kg} / \mathrm{m}^{3}$ for specimens in group B. It is obvious from the figure that concrete specimens in B group have larger shrinkage strain compared to concrete specimens in group A. The reason for the obtained increase of drying shrinkage is due to increasing the unit water content to $225 \mathrm{~kg} / \mathrm{m}^{3}$ and cement content to $450 \mathrm{~kg} / \mathrm{m}^{3}$ (see Table 5), but the $W / C$ and kind of aggregate materials remain the same as group A. It is well known that the drying shrinkage occurs due to the loss of water around cement capillary pores. Therefore, increasing the unit water and cement contents may cause the increase of capillary water amount, and hence more shrinkage strain would be obtained. This implies that unit water content is a major factor on drying shrinkage evolution in concrete specimens.

To show the evidence that drying shrinkage strains at 91 days can be used for evaluating the effect of various aggregate kinds on the drying shrinkage, it is important to show a comparison between drying shrinkage strains measurements at 91 days and 1029 days drying time. The drying shrinkage measurements for concrete specimens at 91 days drying time are plotted versus drying shrinkage measurements for the same concrete specimens at 1029 days drying time, as shown in Fig. 5. It is obvious from the figure that the drying shrinkage strain measurements of investigated concrete specimens have a high correlation coefficient, close to 1.0, for shrinkage strain measurements at 91 and 1029 days drying time. The comparison given in Fig. 5 reveals that the shrinkage strain measurements at 91 days drying time can be used in the discussion of following sections to evaluate the influence of various aggregate characteristics on drying 
shrinkage.

Based on the above discussion about the behavior of drying shrinkage in mortar and concrete specimens, it can be said that the kind of fine aggregate and coarse aggregate materials and their characteristics play an important role in the shrinkage properties of mortar and concrete, respectively. Another important factor which influences the drying shrinkage in concrete is the unit water content. In the following sections, the discussion will be given to the characteristics of aggregate materials and their influence on the drying shrinkage.

\subsection{Relationship between drying shrinkage and mass loss}

The drying condition, or the relative humidity at which the concrete specimens were kept, has a great influence on shrinkage. The curing process of mortar and concrete in a low relative humidity (60\% R.H.) may lead to mass loss of the water retaining in the capillary pores. The fact that the drying shrinkage is caused by the evaporation of capillary water pushed the effort to investigate the drying shrinkage versus the mass loss in mortar and concrete specimens as plotted in Fig. 6.

Figure 6 (a) describes the drying shrinkage-mass loss relationship for all investigated mortar specimens incorporating various kinds of fine aggregate materials. It is evident from the figure that there is almost no distinct correlation between drying shrinkage and mass loss in mortar due to the obtained scatter. Therefore, it can be revealed that the drying shrinkage property is not only related to the mass loss of the capillary water, but also can be affected by fine aggregate physical properties. Also, it is interesting to notice from Fig. 6 that mortars with limestone sand experienced smaller mass loss of water at the same drying shrinkage strain compared to other kinds of fine aggregates mortars. This is due to the chemical reaction between limestone and cement paste which can result in restraining of water mass movement [35].

The relationship between the drying shrinkage and mass loss for all examined concrete specimens made with various kinds of fine and coarse aggregate materials is shown in Fig. 6 (b). Except for Al-A and Al-B concrete specimens with limestone fine aggregate materials, it is obvious that there is a linear relationship between the drying shrinkage and mass loss in concrete, which is represented by the trend line drawn in the figure. The drying shrinkage strains of concrete specimens increase with increase of water mass loss. Also, it is clear that the mass loss of water in andesite concrete specimens with limestone fine aggregates (Al-A and Al-B) is much smaller compared with other concrete specimens, at the same drying shrinkage. This is due to that fact that the transition zone between coarse aggregate and paste system is the weakest area in cement based materials, where the gases and liquids could preferably migrate through this zone in 
concrete. The chemical reaction between limestone and cement paste can significantly improve the bonding stress of the weak interface zone between coarse aggregate and the paste system [35], so that the movement of water mass through this zone can be restrained. Hence, it can be implied that the coarse aggregate materials characteristics have a great influence on the concrete drying shrinkage property.

\subsection{Relationship between drying shrinkage and static modulus of elasticity}

Figures 7 (a) and (b) show the relationship between static modulus of elasticity $(E)$ of 28 days and drying shrinkage strain at 91 days for mortar and concrete specimens, respectively, with various aggregate materials. It is obvious from both figures that for either mortar or concrete specimens the greater the static modulus of elasticity the smaller is the drying shrinkage strain. The concrete specimen with limestone coarse aggregate (Ls-A) showed the smallest shrinkage strain among all concrete specimens due to its relatively great static modulus of elasticity $(E)$, see Fig. 7 (b). This can be explained by the chemical reaction between limestone and cement paste, which enhanced the bonding stress of the interface zone between coarse aggregate and the paste system, resulting in increasing the modulus of elasticity and thus decreasing the shrinkage in turn. In a similar way, BFS mortar specimen experienced the smallest shrinkage among all mortar specimens accompanied with relatively large modulus of elasticity, as shown in Fig. 7 (a). However, the scatter obtained in both figures reveals that there are other influential parameters on drying shrinkage property and not only the effect of static modulus of elasticity of mortar and concrete specimens.

\subsection{Influence of aggregates characteristics on the concrete drying shrinkage}

Since it was revealed that the coarse aggregate materials play a critical role in restraining the drying shrinkage of concrete in the preceding section, the attention will be given in this section to clarify mainly the most influential coarse aggregate characteristics on the drying shrinkage property of concrete, which are coarse aggregate shrinkage strain, specific surface area of aggregate, coarse aggregate pore structure.

\subsubsection{Influence of coarse aggregates shrinkage strain}

It is believed that coarse aggregate accounts for large volumetric ratio in concrete which in turn may influence the drying shrinkage property of concrete. This is why, in this section, the effect of aggregate shrinkage strain on drying shrinkage of concrete was examined. In the previous researches [36, 37], the shrinkage of coarse aggregate was measured until 14 days as the property 
of aggregate. Figure 8 shows the shrinkage strain development versus drying time for different aggregate materials, which are andesite aggregate (A), limestone aggregate (L) and hard sandstone aggregate $(\mathrm{H})$, until two weeks. Each obtained data point shown in the figure for aggregate shrinkage strain is the mean value of shrinkage strain measurements for three coarse aggregate samples with the same conditions, which were placed in the same condition with the investigated concrete specimens. It is clear from Fig. 8 that limestone coarse aggregate (L) experienced the lowest aggregate shrinkage strain, $7.8 \times 10^{-6}$ at two weeks, among the three investigated kinds of coarse aggregates. Conversely, andesite aggregate (A) exhibited the largest aggregate shrinkage strain, $304 \times 10^{-6}$ at two weeks, which is still much smaller than the drying shrinkage strain of andesite concrete.

To clarify the effect of coarse aggregate on the drying shrinkage of concrete, the comparison between coarse aggregate shrinkage strain and concrete drying shrinkage at 91 days is plotted in Fig. 9. It is clear from the figure that a strong correlation between the shrinkage strain of coarse aggregate and drying shrinkage strain of concrete specimens exists, with a determination coefficient $\left(\mathrm{R}^{2}\right)$ of 1.00. The smaller shrinkage strain of coarse aggregate the smaller is the drying shrinkage strain of concrete. This implies that the coarse aggregate not only play a role in restraining the drying shrinkage of concrete, but also play a pole with regard to the drying shrinkage behavior of concrete, and can contribute into its development. Based on the obtained results, the shrinkage of coarse aggregate is not necessary negligible.

\subsubsection{Influence of specific surface area of aggregate materials}

Many researches have been concluded that larger cement-paste specific surface area could cause more drying shrinkage; the finer the pore the greater is the drying shrinkage. However, the influence of specific surface area of aggregate materials on the concrete drying shrinkage has not been appropriately examined. This section tries to investigate this effect on the drying shrinkage development.

It was revealed by Wittmann [38] that above 50\% R.H. the dominant mechanism for drying shrinkage is disjoining pressure. The disjoining pressure mechanism is defined according to Powers and Wittmann [39, 40] as the difference between surfaces of the undisturbed bulk conditions and the interphase, when the distance between those surfaces is less than $3.0 \mathrm{~nm}$. Moreover, it has been proposed by Maruyama and Kishi [41, 42] that the drying shrinakge mechanism could be explained by disjoining pressure as follows: 
Where, $w$ is volumetric water content $\left(\mathrm{m}^{3} / \mathrm{m}^{3}\right), \Delta \Pi$ is incremental disjoining pressure from the reference $\left(\mathrm{N} / \mathrm{mm}^{2}\right), K$ is bulk modulus of hardened cement paste $\left(\mathrm{N} / \mathrm{mm}^{2}\right), \Delta V / V$ is volume change strain of hardened cement paste.

Disjoining pressure (hydration pressure) $\Pi(e)$ as a function of statistical thickness of adsorbed layer $e$ can be obtained as given in Eq. 2.

$\Pi(e)=4500 \times \exp (-2 e / 0.95)$

$e=m_{w} / \rho \cdot \mathrm{S}$

Where, $e$ is statistical thickness of adsorbed layer $(\mathrm{nm}), m_{w}$ is water content by mass $(\%), S$ is specific surface area $\left(\mathrm{m}^{2} / \mathrm{g}\right), \rho$ is density of pore water $\left(\mathrm{g} / \mathrm{m}^{3}\right), \Pi(e)$ is hydration pressure $(\mathrm{MPa})$.

The relationship between the hydration pressure and adsorbed water thickness was given, implying that with the increase of specific surface area the thickness of the absorbed water layer can be reduced. hence the disjoining presuure causing drying shrinkage can be increased leading to larger drying shrinkage. Although there are many factors related to the drying shrinkage, the specific surface area was considered to be an important factor.

The specific surface area of aggregate was measured according to the water vapor adsorption method [32, 33]. The BET calculation method has been the most widely used procedure for the determination of the surface area for solid materials and involves the use of the BET equation. In the experiment, we measured the surface area of aggregate using the single point BET method with relative pressure ratio of $0.3[32,33]$, based on the adsorption of water vapor on a monolayer surface, as expressed in Eqs. 4 and 5:

$V_{m}=V \times\left(1-P / P_{0}\right)$

$A=\left(V_{m} \times N \times a_{m} / M\right) \times 10^{-18}$

where $P / P_{0}$ is Relative pressure, $V_{m}$ is monolayer adsorption capacity $(\mathrm{g} / \mathrm{g}), V$ is total adsorption capacity $(\mathrm{g} / \mathrm{g}), N$ is avagadro's number $\left(6.023 \times 10^{23}\right), M$ is molecular weight of adsorbate $(\mathrm{g}), a_{m}$ is cross sectional area of adsorbate molecular $\left(0.125 \mathrm{~nm}^{2}\right)$.

Figure 10 presents the specific surface area results of three kinds of coarse aggregates, which are andesite aggregate (A), limestone aggregate $(\mathrm{L})$ and hard sandstone aggregate $(\mathrm{H})$, and natural sand fine aggregate (s) as well. From the figure, it can be observed that limestone coarse 
aggregate (L) has the smallest specific surface area and natural sand fine aggregate (s) shows largest specific surface area value among all investigated aggregates. The relationship between coarse aggregate specific surface area and concrete shrinkage strain is discussed in Fig. 11, which can be represented by a linear relationship. The smaller the coarse aggregate specific surface area the less is the drying shrinkage strain of concrete. This is because the smaller specific surface area would cause less shrinkage strain of coarse aggregate, which in turn may develop smaller concrete shrinkage strain.

It is well known that concrete is a composite material made broadly with cement, fine aggregate, coarse aggregate, and water. The relationship between specific surface area of aggregates and drying shrinkage strains of concrete has been investigated by Imamoto et al [26, 32]. Therefore, to consider the influence of aggregates specific surface area on drying shrinkage in concrete, the average specific surface area of both fine and coarse aggregate in the concrete was calculated based on Eq. 6:

$$
A_{\text {mix }}=\left(A_{f} \times M_{f}+A_{c} \times M_{c}\right) /\left(M_{f}+M_{c}\right)
$$

where, $M_{f}, M_{c}$ is absolute dried mass of fine aggregate and coarse aggregate, respectively $\left(\mathrm{g} / \mathrm{m}^{3}\right)$, $A_{f}, A_{c}$ is specific surface area of coarse aggregate and fine aggregate, respectively $\left(\mathrm{m}^{2} / \mathrm{g}\right), A_{\text {mix }}$ is average specific surface area of both fine and coarse aggregate materials $\left(\mathrm{m}^{2} / \mathrm{g}\right)$.

Then, the drying shrinkage strain of concrete is plotted versus the average specific surface area of both fine and coarse aggregates, as shown in Fig. 12. From the figure, it can be said that the concrete drying shrinkage increases with the increase of average specific surface area of aggregates, which shows the significant influence of the aggregates specific surface area on concrete drying shrinkage property. As we know, the specific surface area of aggregate seems to be related to the aggregate pore structure, so the pore size distribution of coarse aggregates is discussed in the following section.

\subsubsection{Influence of coarse aggregates pore structure}

Figure 13 shows the pore size distribution of coarse aggregates measured by the mercury intrusion porosimetry (MIP) method. It is evident from the figure that the limestone coarse aggregate (L) has more large size pores, in particular, and few small size pores. Compared with the limestone coarse aggregate, the andesite coarse aggregate (A) and hard sandstone coarse aggregate $(\mathrm{H})$ exhibited a different pore size distribution with more small size pores less than 50 $\mathrm{nm}$ and few large size pores. The fact that the coarse aggregate with more small size pores and few large size pores can result in small specific surface area can be confirmed in the case of 
limestone coarse aggregate (L), which showed a relatively smaller specific surface area compared to andesite coarse aggregate, as discussed in section 3.4.2. This implies that the coarse aggregate specific surface area is strongly correlated with the pore structure of aggregate.

The mechanism of porosity structure and drying shrinkage of cement hardened paste is that the formation of the liquid-vapor in the pores can ultimately lead to shrinkage, which is also applied in the coarse aggregate. In addition, based on the previous research findings [43], generally, at 55 to $60 \%$ relative humidity, the diameter of the capillary pore, which is involved in the drying shrinkage, is assumed to be $30 \mathrm{~nm}$ or less. Besides, in the laboratory, the mercury intrusion porosimetry cannot be applied to measure the volume of $6 \mathrm{~nm}$ diameter pores or less. Therefore, the relationship between the concrete drying shrinkage and pore volume of 6 to $30 \mathrm{~nm}$ diameter is plotted in Fig. 14. It was found that there is a high positive correlation between the concrete drying shrinkage and aggregate pore structure. With the increase of pore volume of 6 to $30 \mathrm{~nm}$ in diameter, the shrinkage strain of concrete has the tendency to increase. The discussion reveals that the coarse aggregate pore structure is also another influential parameter on the concrete drying shrinkage.

\subsection{Relationship between total amount of water in concrete and concrete drying shrinkage}

The moisture content of an aggregate is an important parameter in any cementitious material. This is the reason that the relationship between the water absorption ratio of aggregate and concrete drying shrinkage is given in Fig. 15. It is clear that the higher water absorption ratio the more is the drying shrinkage strain. It can be revealed that the water absorption ratio of aggregate is also related to the shrinkage property.

It is worthy to mention, based on the current investigation of drying shrinkage property, that the drying shrinkage of concrete can be affected not only by the characteristics of aggregate materials but also by unit water content, as discussed in section 3.1.2. Thus, the influence of water content could not be expounded clearly only by coarse aggregate water absorption ratio. This is why it is more reasonable to investigate the effect of total amount of water in concrete on drying shrinkage property. The total amount of water in concrete represents the influential parameters on drying shrinkage, which are water absorption ratio, unit mass of aggregate and unit water content [44]. It can be calculated by the following Eq. 6:

$$
W=\left(W_{w}+W_{f} \times R_{f}+W_{c} \times R_{c}\right)
$$

Where $W$ is total amount of water in concrete $\left(\mathrm{kg} / \mathrm{m}^{3}\right), W_{w}$ is unit water content $\left(\mathrm{kg} / \mathrm{m}^{3}\right), W_{f}, W_{c}$ is 
unit mass of fine aggregate and coarse aggregate, respectively $\left(\mathrm{kg} / \mathrm{m}^{3}\right), R_{f}, R_{c}$ is water absorption ratio of fine aggregate and coarse aggregate, respectively $(\%)$.

Figure 16 discusses the relationship between the total amount of water in concrete and the drying shrinkage strain. As a general behavior, the drying shrinkage strain becomes larger with the increase of total amount of water, showing a high correlation. Moreover, it is worthy to mention that the influence of the total amount of water in concrete on the drying shrinkage development is also associated with the static modulus of elasticity $(E)$ of the concrete. Concrete specimens with higher water content would produce a smaller strength and smaller modulus of elasticity as well, implying that the concrete has a high tendency to have more shrinkage. This is consistent with what discussed in the previous section 3.3.

Based on the above discussion, it can be concluded that the concrete shrinkage could be controlled by the total amount of water, in which water absorption ratio, unit mass of aggregate and unit water content were considered, and the static modulus of elasticity of concrete. Also, the coarse aggregate characteristics, which are coarse aggregate shrinkage strain, specific surface area of aggregate materials and pores structure of coarse aggregate, can play an important role in concrete drying shrinkage evolution.

\section{Conclusions}

The objective of this study is to clarify experimentally the influence of the aggregate materials characteristics, which are coarse aggregate shrinkage strain, specific surface area of aggregate materials, water absorption ratio and pores structure of coarse aggregate, on the drying shrinkage property of mortar and concrete specimens. Fourteen kinds of fine aggregate materials and three kinds of coarse aggregate materials were investigated in the study. Based on the experimental results, the main findings of this study, which are useful information for enhancing the existing design practices for drying shrinkage control, can be drawn as follows:

1. For mortar specimens, the drying shrinkage strains in investigated mortars were changed significantly by different kinds of fine aggregate materials. While, for concrete specimens, the fine aggregates showed inconsiderable effect due to the less volume portion. The primarily affecting factors on drying shrinkage development in concrete specimen are the kind of coarse aggregate and their characteristics, such as coarse aggregate shrinkage strain, specific surface area of aggregate, absorption ratio and pore structure of coarse aggregate.

2. It was also found that unit water content of the concrete mix proportion is a major factor on drying shrinkage evolution in concrete specimens. Increasing the unit water content can result in the increase of capillary water amount, and hence more shrinkage strain would be obtained. 
3. It was clarified that drying shrinkage strain of concrete can be increased by the increase of water mass loss, and conversely with the decrease of the static modulus of elasticity. The limestone aggregate can effectively reduce the drying shrinkage strain of concrete specimens with small mass loss. This is due to the fact that the bonding stress of the weak interface zone between the coarse aggregate and cement paste, where the gases and liquids could preferably migrate, can be improved by the chemical reaction between limestone and cement paste.

4. The test results revealed that the smaller the coarse aggregate shrinkage strain the less is the drying shrinkage strain of concrete, which means that the coarse aggregate not only play a role in restraining the drying shrinkage of concrete, but also play a pole with regard to the drying shrinkage development of concrete.

5. It was disclosed that the drying shrinkage strain of concrete specimens proportionally increases with both the increase of average specific surface area and volume of 6 to $30 \mathrm{~nm}$ in diameter pore structure of aggregates, which implies the significant influence of aggregate characteristics on drying shrinkage development in concrete.

6. The parameter total amount of water, which can be calculated by considering the water absorption ratio, unit mass of aggregate, and unit water content, was presented to evaluate the drying shrinkage property of concrete. It was revealed that the drying shrinkage strain becomes larger with the increase of total amount of water. Finally, it was concluded that the concrete shrinkage can be controlled by reducing the total amount of water, and appropriate aggregate characteristics as well.

\section{References:}

[1] Eguchi K, Teranishi K. Prediction equation of drying shrinkage of concrete based on composite model. Cem Concr Res 2005;35(3): 483-93.

[2] Güneyisi E, Gesoglu M, Ozaby E. Strength and drying shrinkage properties of self-compacting concretes incorporating multi-system blended mineral admixtures. Constr Build Mater 2010;24(10):1878-87.

[3] Zhang W, Zakaria M, Kishimoto Y, Hama Y. Drying shrinkage and microstructure characteristics of ground granulated blast furnace slag-cement mortar. Proc Jpn Concr Inst 2012;34(1): 388-93.

[4] Farshad R, Gaurav S, Jason W. Interactions between shrinkage reducing admixtures (SRA) and cement paste pore solution. Cem Concr Res 2008;38(5): 606-15.

[5] Mario C, Antonio B, Silvia C, Jean O. Effects of shrinkage reducing admixtures in shrinkage compensating concrete under non-wet curing conditions. Cem Concr Res 2005;27(6):704-8.

[6] Narumi R, Zhang W, Kishimoto Y, Hama Y. Influence of pore structure on shrinkage properties and frost resistance of mortar using SRA. Proc Jpn Concr Inst 2012;34(1): 148-53 [in Japanese].

[7] Architectural Institute of Japan. Japanese Architectural Standard Specification JASS 5 -- reinforced concrete work; 2009.

[8] Debieb F, Kenai S. The use of coarse and fine crushed bricks as aggregate in concrete. Constr Build Mater 2008;22(5): 886-93.

[9] Kenai S, Benna Y, Menadi B. The effect of fines in crushed calcareous sand on properties of mortar and concrete. In: Proc int conf on infrastructure regeneration and rehabilitation. Sheffield, 1999: 253-61.

[10] Appa Rao G. Long-term drying shrinkage of mortar-influence of silica fume and size of fine aggregate. Cem Concr Res 2001; 31(2):171-5.

[11] Quan N. The application of copper slag in the concrete. Summaries of technical paper of architectural research 
meeting of AIJ, 1996: 443-4.

[12] Imamoto K, Ishii S, Arai M. Drying shrinkage characteristic of concrete using kinds of aggregates and the influence of aggregate specific surface area. J Struct Constr Eng 2006; 8(606):9-14.

[13] Sakamoto R, Nakata Y, Otsuka S. Literature study on influence of drying shrinkage on mix proportion and coasrse aggregate. Proc Jpn Concr Inst 2009; 31(1): 583-8.

[14] Troxell G D, Raphael J M, Davis R E. Long-time creep and shrinkage tests of plain and reinforced concrete. Proc ASTM 1958; 58:1101-20.

[15] Hansen T, Nielsen K. Influence of aggregate properties on concrete shrinkage. J Am Concr Inst 1965;62 (7): 783-94.

[16] Zhang W, Sun W. Effect of coarse aggregate on early age autogenous shrinkage of high-performance concrete. J Chin Ceram Soc 2009;37(4): 631-6.

[17] Hobbs D W. Influence of aggregate restraint on the shrinkage of concrete. J Am Concr Inst 1974;71(9): 445-50.

[18] Tanaka H. Influence of kind of aggregates on the drying shrinkage of concrete. Proc Jpn Concr Inst, Vol. 31, No. 1, 2009, pp. 553-558 [in Japanese].

[19] Andrés I, Jan B, Antonio C, Pietro L. A numerical and experimental study of aggregate-induced shrinkage cracking in cementitious composites. Cem Concr Res 2012; 42(2):272-81.

[20] Limestone Association of Japan: Limestone aggregate and concrete, 2005.

[21] Tarun R, Rudolph n K, Yoon-mood, C. Effect of different types of aggregates on autogenous and drying shrinkage of concrete. In: Proc first Int conf on advanced construction materials 2006:147-60.

[22] Fujiwara T. Effect of aggregate on drying shrinkage of concrete. J Adv Concr Technol 2008; 6(1):31-44.

[23] Tanaka H, Hashida H. Effect of limestone as aggregate on reducing drying shrinkage of concrete. In: Proc of CONCREEP 8 conf 2008;2: 877-83.

[24] Snowdon LC, Edwards A G. The moisture movement of natural aggregate and its effect on concrete. Mag Concr Res 1962;14(41):109-16.

[25] Goto Y, Fujiwara T. Volumetric change of aggregates by absorption and drying. Jpn Soc of Civil Engineers, 1978; (247).

[26] Seisui K, Imamoto K, Arai M. Relation between concrete shrinkage strain and specific surface area measured by BET single point. In: Annual meeting JCA 2010; 5:44-5.

[27] Shi D, Ma Z, Wu A. Study on drying shrinkage properties of concrete using blast furnace slag as fine aggregate. Applied Mechanics and Materials 2012;174: 539-44.

[28] Yamada H, Katahira H, Watanabe H. Study on the evaluation for drying shrinkage properties of coarse aggregate. J Jpn Soc Civil Engineers 2012;68(1): 63-71.

[29] Kayyali O. Mercury intrusion porosimetry of concrete aggregate. Mater Struct 1985; 18(106): 259-62.

[30] Tatematsu K, Arai M, Iwashimizu T, Kimura Y. Experimental study on drying shrinkage and pore size distribution of aggregate in kansai area. J Struct Constr Eng 200; (549): 1-6 [in Japanese].

[31] Na S, Hama Y, Taniguch M, Katsura O, Sagawa T, Zakaria M. Experimental investigation on reaction rate and self-healing ability in fly ash blended cement mixtures. J Adv Concr Technol 2012; 10: 240-53.

[32] Imamoto K, Arai M. Simplified evaluation of shrinking aggregate based on BET surface area using water vapor. J Adv Concr. Technol 2008; 6 (1): 69-75.

[33] Kinto D, Ishiikawa T, Abe I. Science of adsorption, maruzen press, 2001 [in Japanese].

[34] Adolphs J. Excess surface work - A modelless way of getting surface energies and specific surface areas directly from sorption isotherms. Appl Surf Sci 2007; 253:5645-9.

[35] Peter H, Paul T, Rachel D. The use of limestone in Portland cement: A state of the art review. 2003.

[36] Hyodo H, Isaka Y, Tanimura M, Sato R. Effect of aggregate character and shrinkage reducing material on drying shrinkage of concrete. Proc Jpn Concr Inst 2010; 32(1):377-82.

[37] Hyodo H, Tanimura M, Isaka Y, Sato R. Influence of aggregate properties on drying shrinkage of concrete. Proceeding of JCI symposium on Evaluation of Concrete Shrinkage and its Effect 2010, Dec;17-24.

[38] Wittmann. F. H., Heresies on shrinkage and creep mechanisms. Creep, Shrinkage, and Durability Mechanics of Concrete and Concrete Structures, Tanabe et al.(eds), Taylor \& Francis, 2009; (1):3-10.

[39] Powers, T.C., Mechanism of shrinkage and reversible creep of hardened cement paste, Proc International Conference On the Structure of Concrete, Cement and Concrete Association, London, 1968; 319-44.

[40] Wittmann. F. H., Interaction of hardened cement paste and water. J. Am. Ceram. Soc. 1973; 56(8): 409-15.

[41] Maruyama. I., Kishi. N., Theory of shrinkage of hardened cement paste. Journal of Structural and Construction Engineering 2009; 74(642):1395-1403.

[42] Maruyama. I., Origin of Drying Shrinkage of Hardened Cement Paste: Hydration Pressure. J Adv Concr Technol 2010; 8: 187-200.

[43] Bentur A. Influence of microstructure on the creep and drying shrinkage of calcium silicate pastes. In: Proc of 7th Int congress on the chemistry of cement, III (VI) 1980: 26-31.

[44] Fukushima S, Hashimoto S. A study on the influence of shrinkage on the concrete using the aggregate with high absorption. In: Proc of the Jpn Concr Inst 2007; 29(1): 645-50. 
Table 1 Physical and chemical properties of cement.

\begin{tabular}{cc}
\hline Oxide $(\%)$ & Value \\
\hline $\mathrm{SiO}_{2}(\%)$ & 21.06 \\
$\mathrm{Al}_{2} \mathrm{O}_{3}(\%)$ & 5.51 \\
$\mathrm{Fe}_{2} \mathrm{O}_{3}(\%)$ & 2.69 \\
$\mathrm{CaO}(\%)$ & 65.47 \\
$\mathrm{MgO}(\%)$ & 1.66 \\
$\mathrm{~K}_{2} \mathrm{O}(\%)$ & 0.40 \\
$\mathrm{Na}_{2} \mathrm{O}(\%)$ & 0.24 \\
$\mathrm{SO}_{3}(\%)$ & 1.91 \\
\hline Density $\left(\mathrm{g} / \mathrm{cm}^{3}\right)$ & 3.17 \\
Blaine $\left(\mathrm{cm}^{2} / \mathrm{g}\right)$ & 3390 \\
\hline
\end{tabular}

Table 2 Physical properties of aggregate materials.

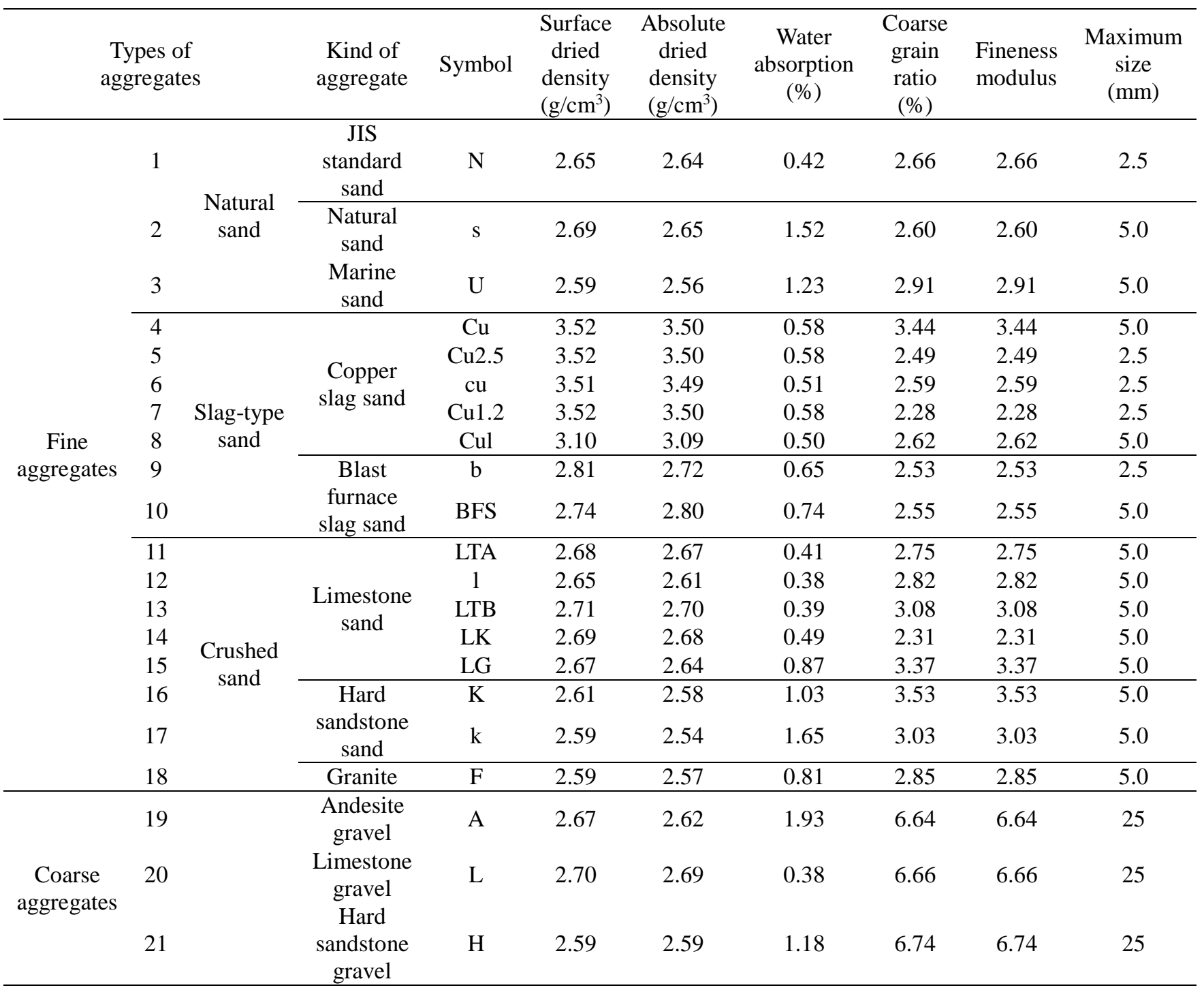


Table 3 Mix proportion of mortar incorporating JIS

\begin{tabular}{cccccc}
\multicolumn{6}{c}{ standard sand. } \\
\hline Symbol & $\begin{array}{c}W / C \\
(\%)\end{array}$ & $C: S$ & $\begin{array}{c}W \\
\left(\mathrm{~kg} / \mathrm{m}^{3}\right)\end{array}$ & $\begin{array}{c}C \\
\left(\mathrm{~kg} / \mathrm{m}^{3}\right)\end{array}$ & $\begin{array}{c}S \\
\left(\mathrm{~kg} / \mathrm{m}^{3}\right)\end{array}$ \\
\hline $\mathrm{N}$ & 50 & $1: 3$ & 256 & 513 & 1542 \\
\hline
\end{tabular}

$C$ : ordinary Portland cement

$W / C$ : water-to-cement ratio

$C: S$ : cement-to-sand ratio

Table 4 Aggregate materials used in concrete.

\begin{tabular}{ccc}
\hline Symbol & $\begin{array}{c}\text { Coarse } \\
\text { aggregates }(G)\end{array}$ & Fine aggregates $(S)$ \\
\hline As & Andesite & Natural sand \\
Ls & Limestone & Natural sand \\
Hs & Hard & Natural sand \\
& sandstone & Hard sandstone sand \\
Acuk & Andesite & $+30 \%$ Copper slag \\
& & Hard sandstone sand \\
Abk & Andesite & $+30 \%$ BFS \\
Al & Andesite & Limestone sand \\
Ak & Andesite & Hard sandstone sand \\
\hline
\end{tabular}


Table 5 Mix proportions and fresh properties of concrete.

\begin{tabular}{|c|c|c|c|c|c|c|c|c|c|c|}
\hline \multirow{2}{*}{\multicolumn{2}{|c|}{ Group Symbol }} & \multirow{2}{*}{$W / C(\%)$} & \multirow{2}{*}{$\begin{array}{c}S /(G+S) \\
(\%)\end{array}$} & \multicolumn{5}{|c|}{ Unit mass $\left(\mathrm{kg} / \mathrm{m}^{3}\right)$} & \multirow{2}{*}{$\begin{array}{l}\text { Slump } \\
(\mathrm{mm})\end{array}$} & \multirow{2}{*}{$\begin{array}{c}\text { Air content } \\
(\%)\end{array}$} \\
\hline & & & & $C$ & $W$ & & $S$ & $G$ & & \\
\hline \multirow{7}{*}{$\mathrm{A}$} & As-A & \multirow{11}{*}{50} & 46 & 370 & 185 & 850 & & 993 & 175 & 3.0 \\
\hline & Ls-A & & 46 & 370 & 185 & 850 & & 1005 & 180 & 2.9 \\
\hline & Hs-A & & 46 & 370 & 185 & 850 & & 978 & 190 & 2.3 \\
\hline & Acuk-A & & 46 & 370 & 185 & k 573 & cu 334 & 993 & 35 & 3.2 \\
\hline & Abk-A & & 46 & 370 & 185 & k 573 & b 267 & 993 & 35 & 3.3 \\
\hline & $\mathrm{Al}-\mathrm{A}$ & & 46 & 370 & 185 & 838 & & 993 & 30 & 4.4 \\
\hline & Ak-A & & 46 & 370 & 185 & 819 & & 993 & 35 & 2.8 \\
\hline \multirow{4}{*}{ B } & Acuk-B & & 40.3 & 450 & 225 & $\mathrm{k} 456$ & cu 263 & 993 & 190 & 1.6 \\
\hline & Abk-B & & 40.3 & 450 & 225 & k 456 & b 211 & 993 & 180 & 1.8 \\
\hline & Al-B & & 40.3 & 450 & 225 & 665 & & 993 & 195 & 2.3 \\
\hline & Ak-B & & 40.3 & 450 & 225 & 650 & & 993 & 175 & 1.5 \\
\hline
\end{tabular}




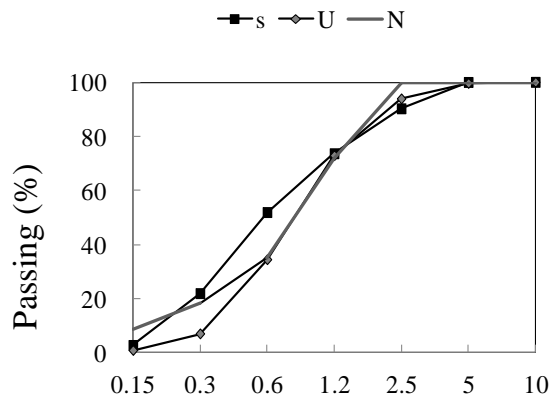

Sieve size (mm)
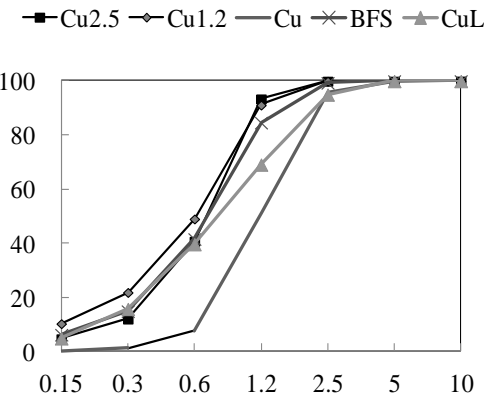

Sieve size $(\mathrm{mm})$

(b) Slag-type sand

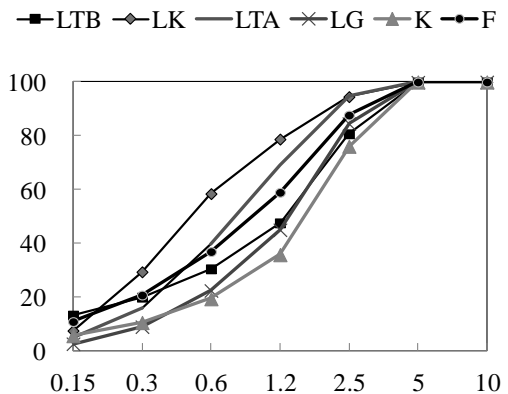

Sieve size (mm)

(c) Crushed sand

Fig. 1 Particle size distribution of fine aggregate used in mortar specimens.

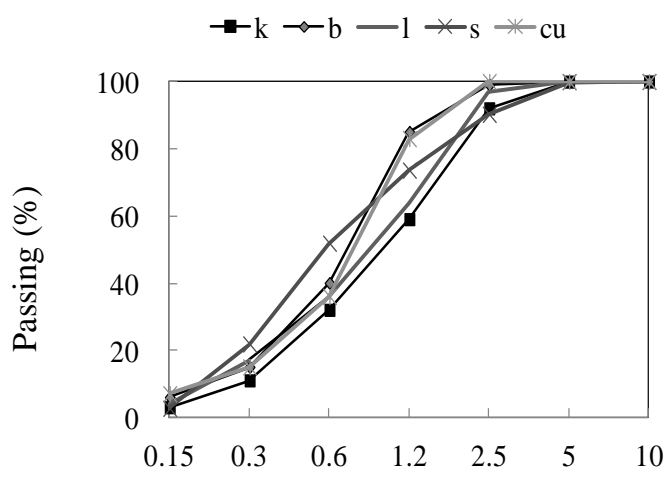

Sieve size (mm)

(a) Fine aggregate

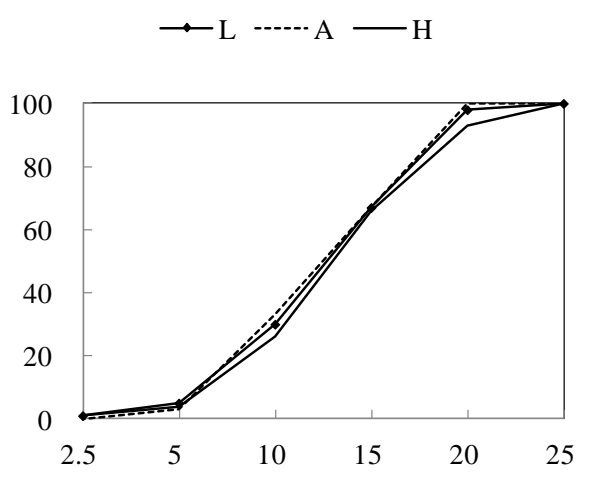

Sieve size (mm)

(b) Coarse aggregate

Fig. 2 Particle size distribution of fine and coarse aggregates used in concrete specimens. 


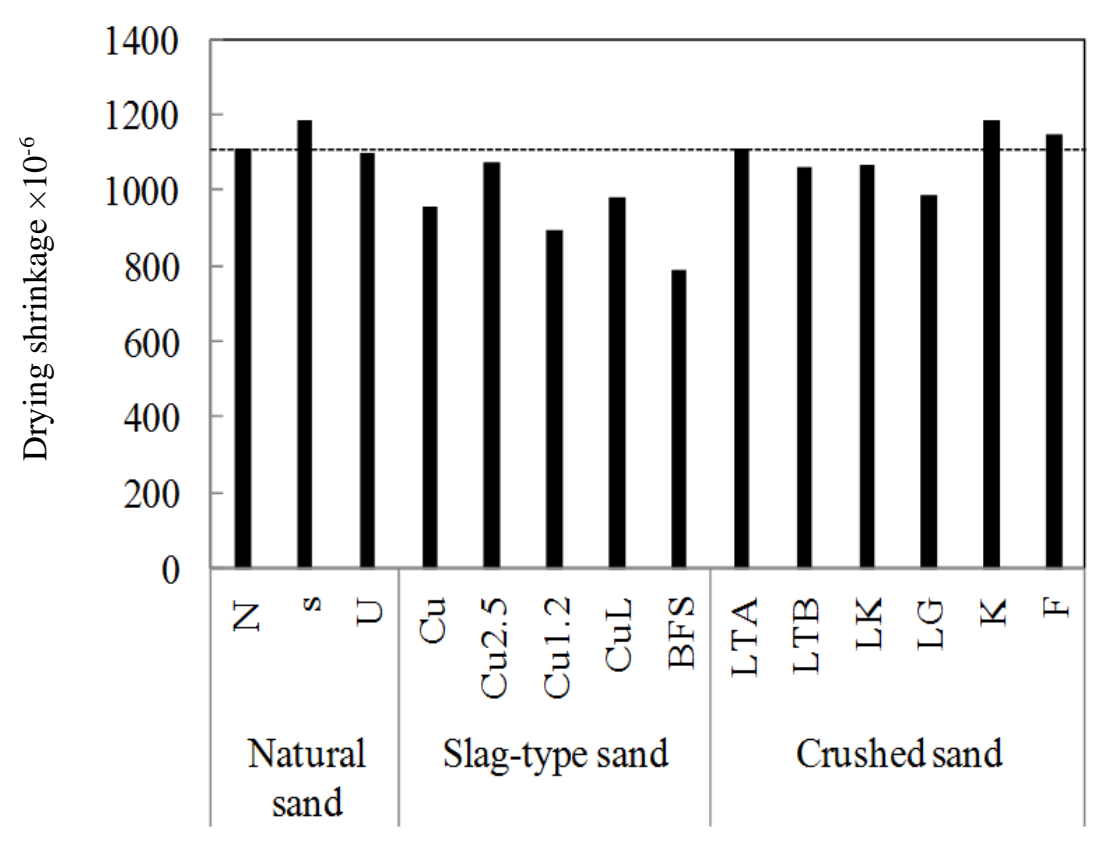

Mortar specimens

Fig.3 Drying shrinkage in mortar specimens.

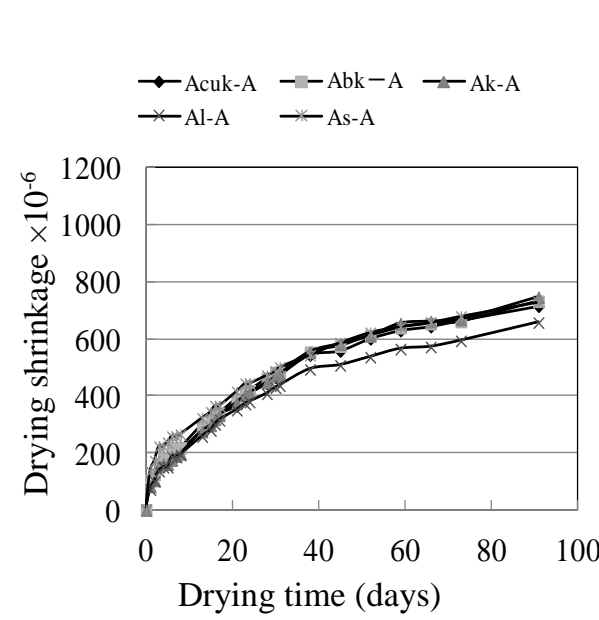

(a) Influence of fine aggregates

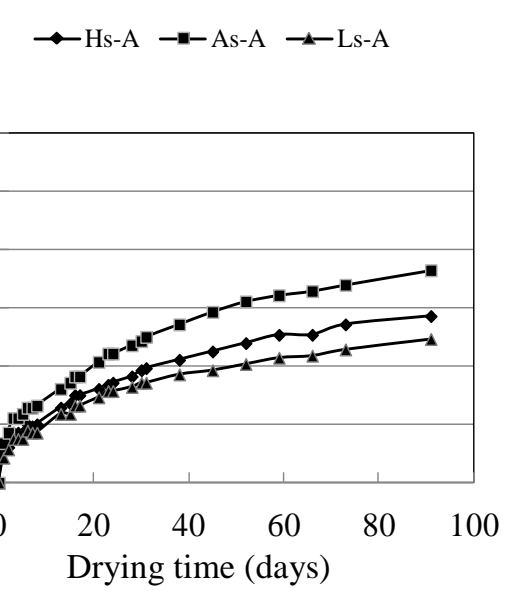

(b) Influence of coarse aggregates
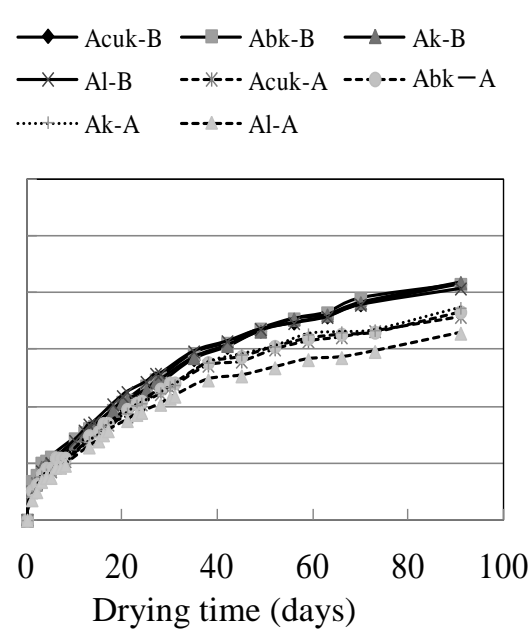

(c) Influence of unit water

Fig. 4 Drying shrinkage evolution in concrete specimens. 


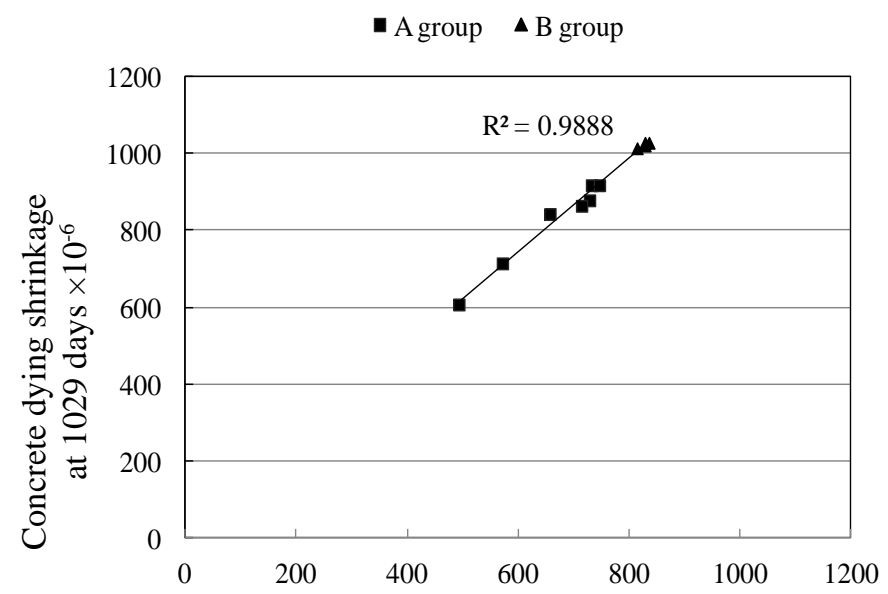

Concrete dying shrinkage at 91 days $\times 10^{-6}$

Fig. 5 Comparison for concrete drying shrinkage at different drying times.

A group (Unit water content $185 \mathrm{~kg} / \mathrm{m}^{3}$ )

B group (Unit water content $225 \mathrm{~kg} / \mathrm{m}^{3}$ )

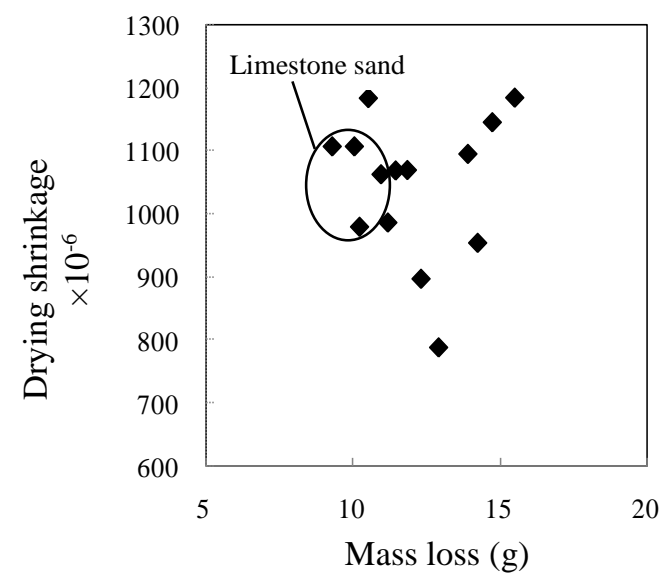

(a) Mortar

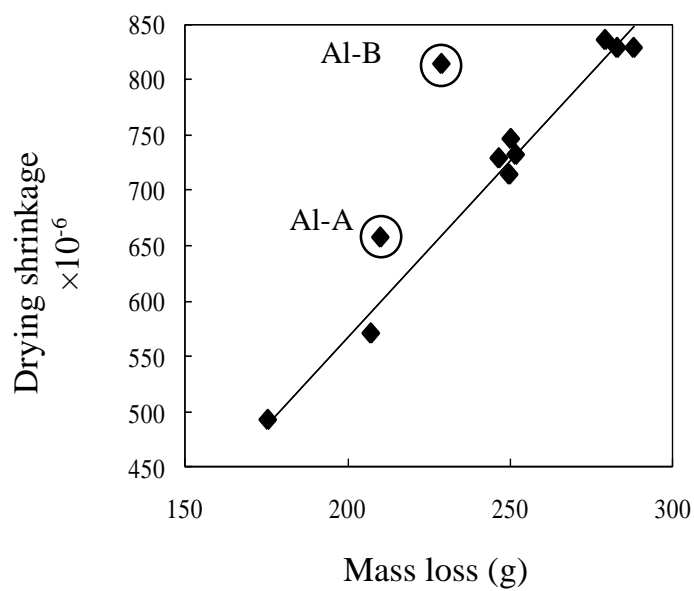

(b) Concrete

Fig. 6 Correlation between drying shrinkage and water mass loss. 


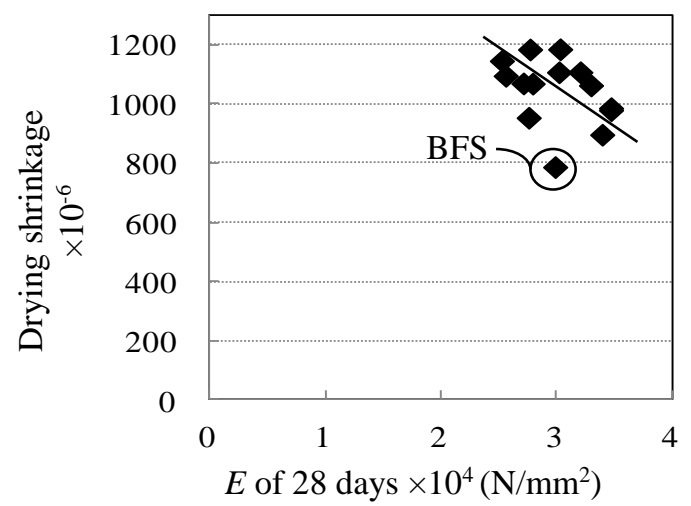

(a) Mortar

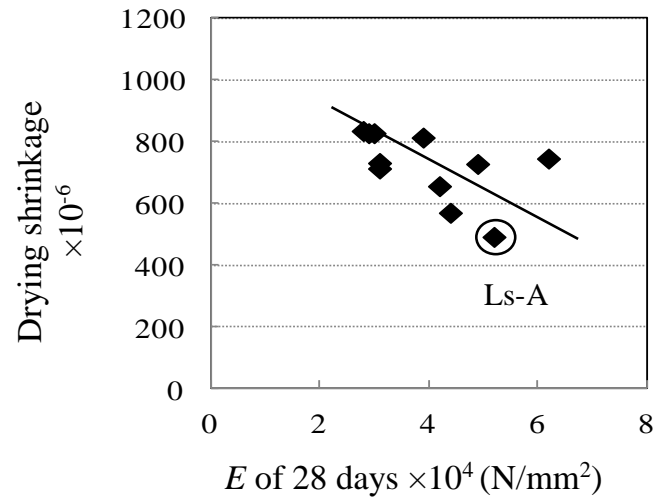

(b) Concrete

Fig. 7 Relationships between drying shrinkage and static modulus of elasticity.

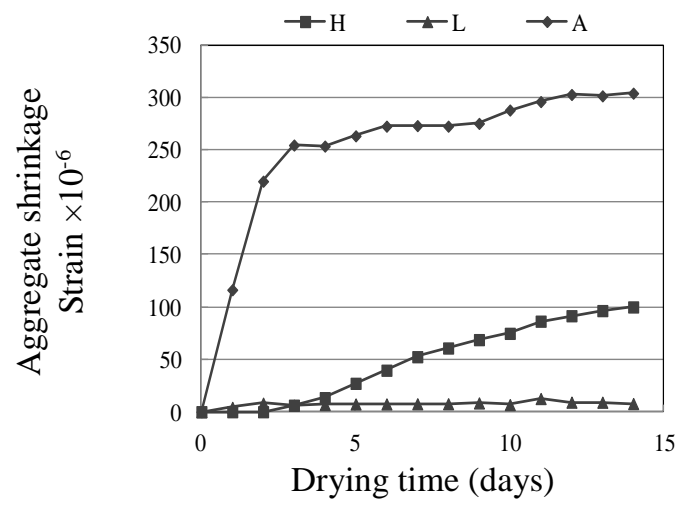

Fig. 8 Development of coarse aggregate shrinkage strain.

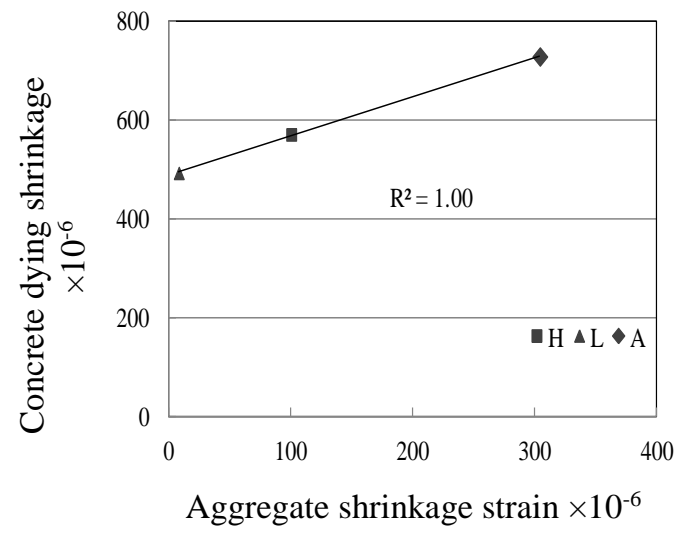

Fig. 9 Relationship between drying shrinkage and aggregate shrinkage strain. 


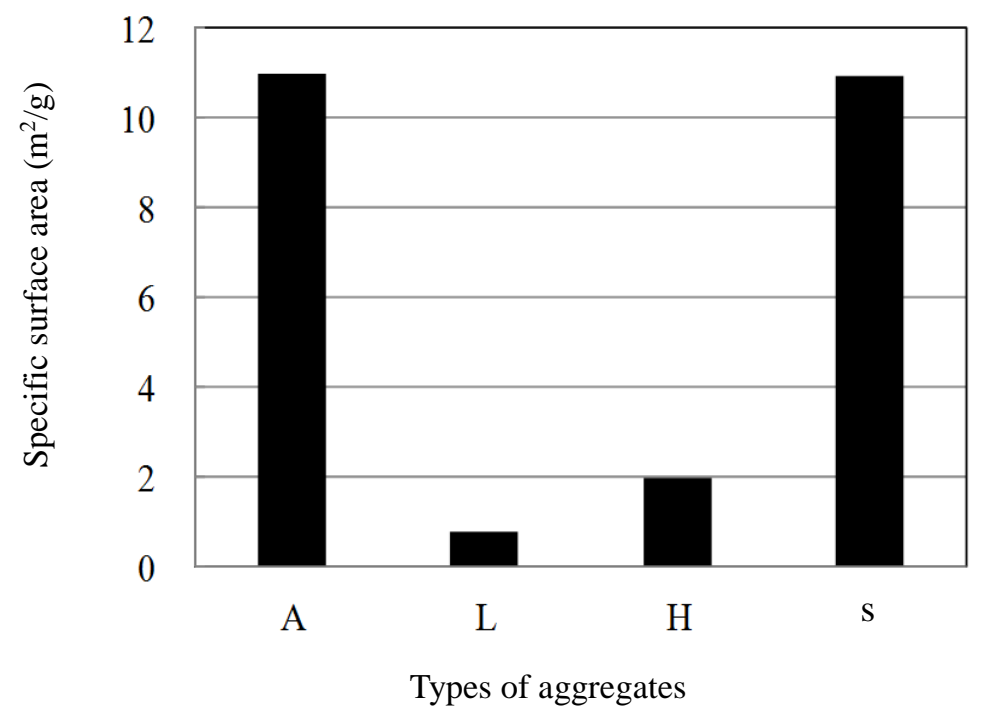

Fig. 10 Specific surface area results of aggregates.

$\mathrm{s}$ : refers to the fine aggregate - natural sand

A, L, H: refer to the coarse aggregates - Andesite, limestone and hard sandstone, respectively.

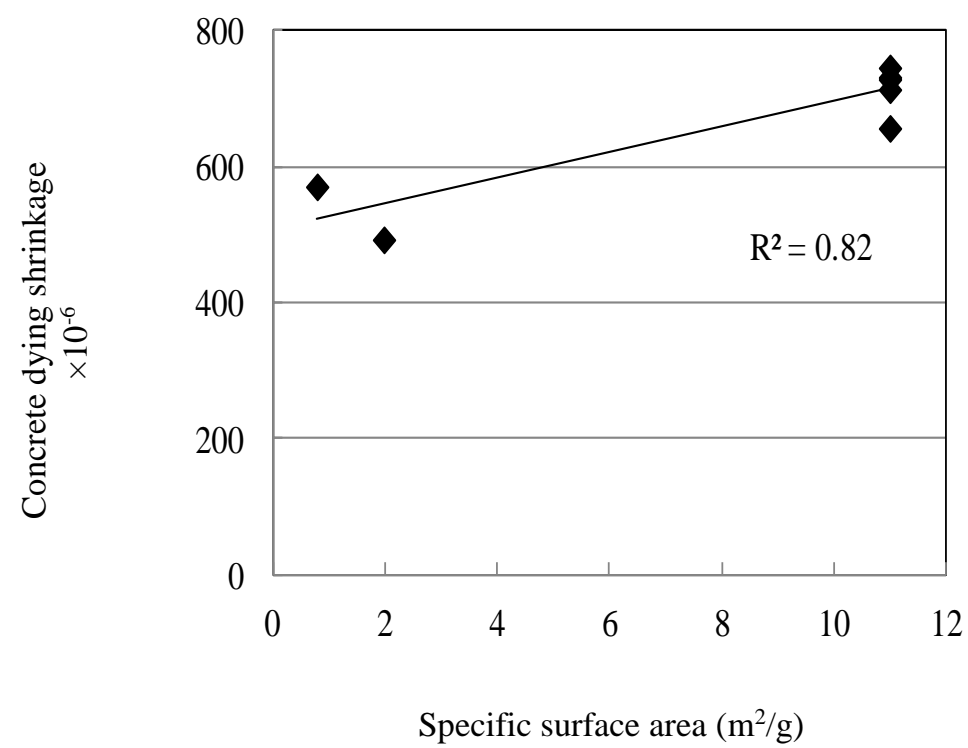

Fig. 11 Relationship between the specific surface area of coarse aggregate and drying shrinkage of concrete. 


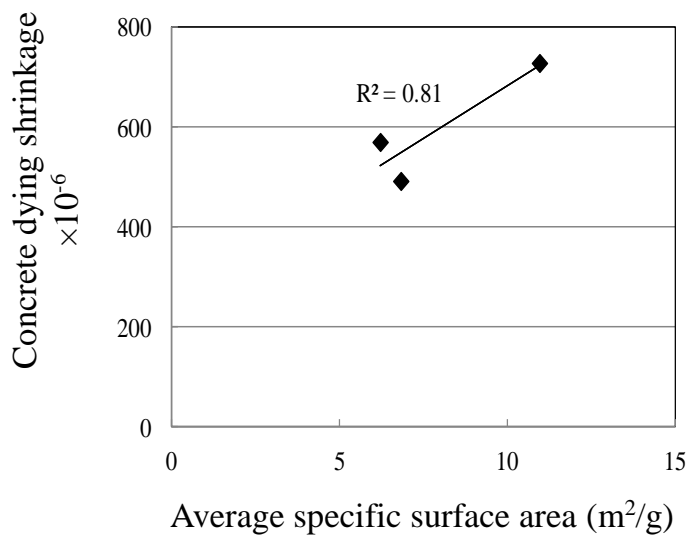

Fig. 12 Relationship between the average specific surface area of aggregate and concrete drying shrinkage.

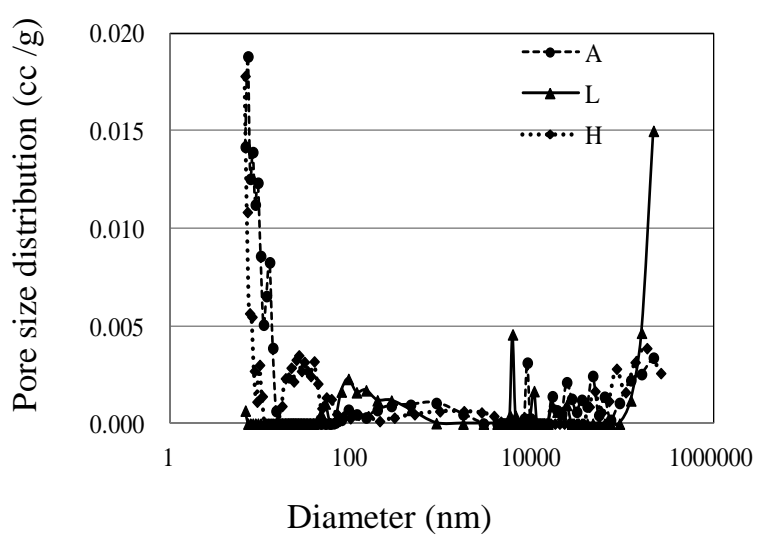

Fig. 13 Pore size distribution of coarse aggregates.

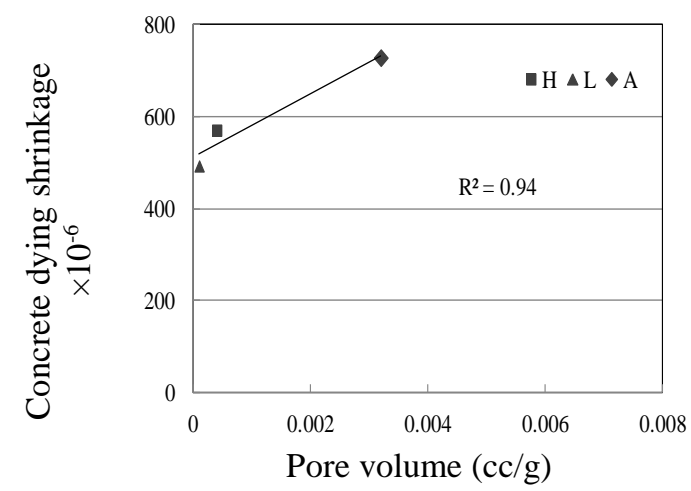

Fig. 14 Relationship between pore volume of 6 to $30 \mathrm{~nm}$ diameter and concrete drying shrinkage. 


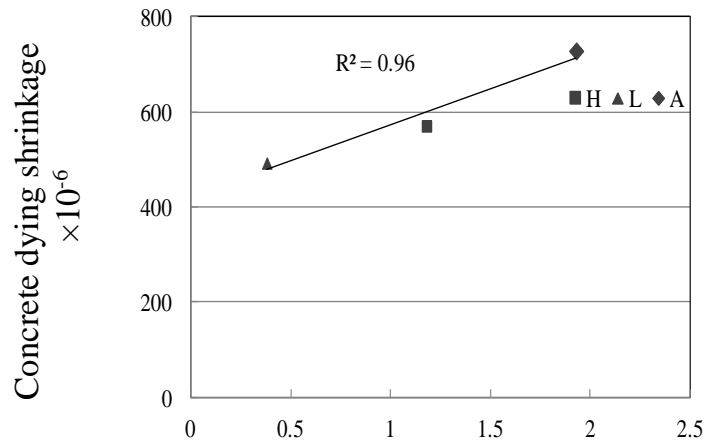

Water absorption ratio (\%)

Fig. 15 Relationship between aggregate water absorption ratio and concrete drying shrinkage.

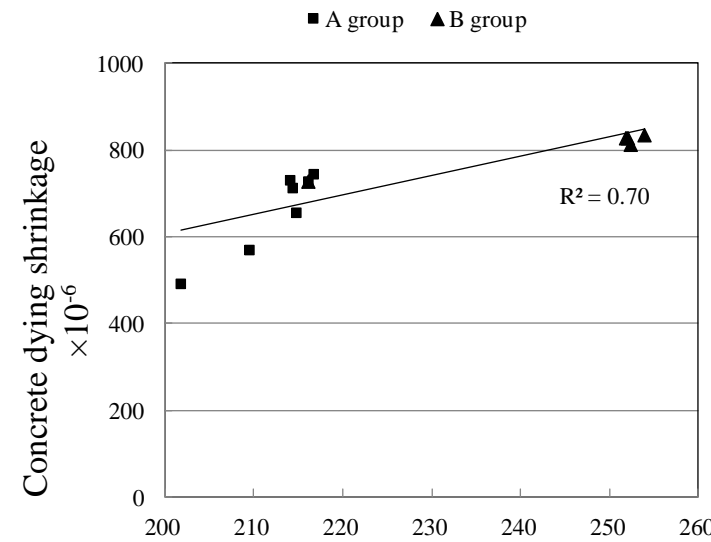

Total amount of water in concrete $\left(\mathrm{kg} / \mathrm{m}^{3}\right)$

Fig. 16 Relationship between the total amount of water and drying shrinkage of concrete.

A group (Unit water content $185 \mathrm{~kg} / \mathrm{m}^{3}$ )

B group (Unit water content $225 \mathrm{~kg} / \mathrm{m}^{3}$ ) 